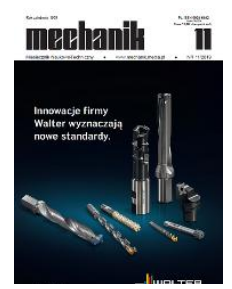

How to cite this article:

Authors: Jan Burek, Rafał Flejszar

Title of article: „Simulation analysis of the wrap angle in internal corners finishing milling”

Mechanik, No. 11 (2019)

DOI: https://doi.org/10.17814/mechanik.2019.11.97

\title{
Simulation analysis of the wrap angle in internal corners finishing milling
}

\author{
JAN BUREK \\ RAFAŁ FLEJSZAR *
}

Dr hab. inż. Jan Burek, prof. PRz, jburek@prz.edu.pl, https://orcid.org/0000-0003-2664-5248 - Katedra Technik Wytwarzania i Automatyzacji, Wydział Budowy Maszyn i Lotnictwa, Politechnika Rzeszowska im. Ignacego Łukasiewicza, Rzeszów, Polska

Mgr inż. Rafał Flejszar, r.flejszar@prz.edu.pl, https://orcid.org/0000-0001-5231-6494 - Katedra Technik Wytwarzania i Automatyzacji Wydział Budowy Maszyn i Lotnictwa, Politechnika Rzeszowska im. Ignacego Łukasiewicza, Rzeszów, Polska

The simulation of the cutting layer in the CAD system during milling internal corners of elements with complex geometry has been presented. A case of variable cutting width in the finishing process was considered and the strategy of multitransitional corner milling was analyzed.

KEYWORDS: concave corners, cutting layer analysis, machining strategies

\section{Introduction}

In the milling process one of the fundamental problems is finishing of internal corners with a small rounding radius. The problem is mainly driven, among other things, by irregular cutting width for the last finishing pass. This is justified on economic grounds: material rough machining with milling cutter with larger diameter is much more effective than with milling cutter for finishing machining. This increases cutting width, which in turn results in major change the wrap angle (fig. 1) $[1,2,5]$.

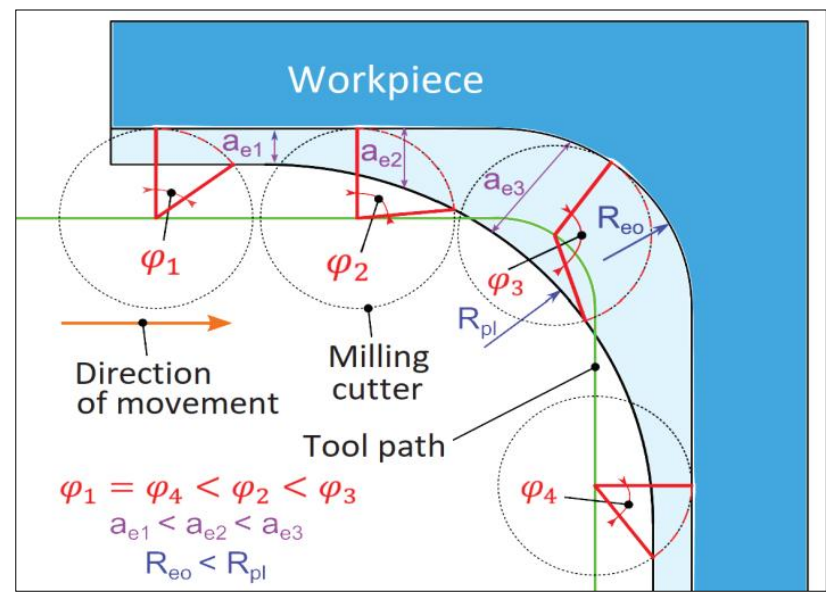

Fig. 1. Changing the wrap angle $\varphi$ when milling an inner corner with a variable cutting width $a_{\mathrm{e}}$

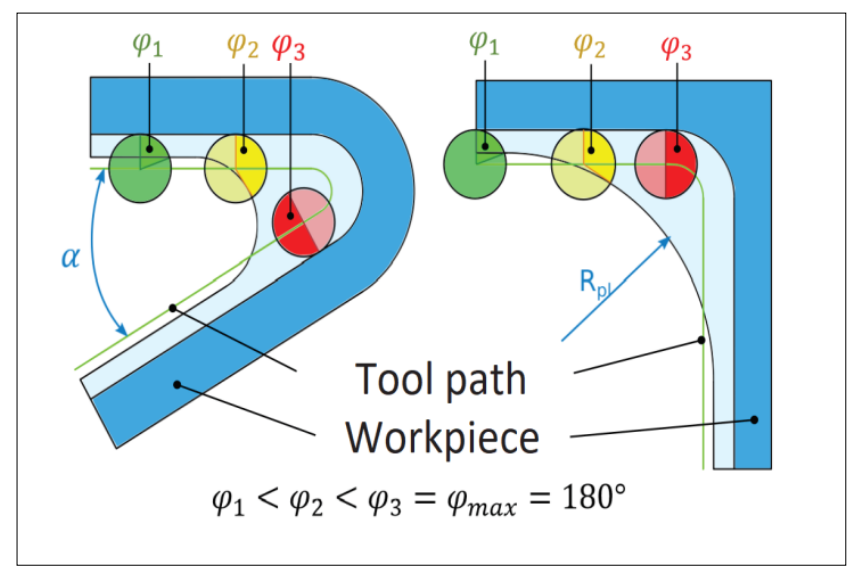

Fig. 2. Impact of the rounding radius of the blank $R_{\mathrm{pl}}$ and the angle of adjacent walls $\alpha$ of the workpiece on the strategy of single-pass finishing milling

Changing the wrap angle directly affects cross-sectional area of the machined layer and contact area of the tool with the workpiece, and therefore - significant increase of machining forces. This can lead to vibrations, which contribute to significant deterioration in the accuracy of the produced elements during finishing milling. If the mill with a large diameter is to be used for rough machining or in the case of the occurrence of acute angle between machined paths it may be that mill will work over the entire wrap angle range, this would result in its or workpiece damage. (fig. 2) [1-3, 6]. 
In order to reduce such problems applies:

- feed reduction,

- use another tool,

- increase in the number of finishing passes.

Most popular solution is feed modification, however, this causes not only decrease machining capacity, but also - and above all - changing milling conditions. Tools manufacturers shall provide recommended feed correction values depending on workpiece geometry and mill wrap angle, in reality this parameter should be controlled according to strictly defined function, what allow only complex mathematical algorithms or commercial optimizing software. Use of several shaping passes before performance of right finishing machining seems to be more reasonable $[4,6,7]$.

The purpose of the study was to analyse machining layer during internal corners milling and verify wrap angle values on the strategy of multi-pass finishing milling.

\section{Method of simulation tests}

Parameterized three-dimensional blank models and simplified model of tool were prepared for simulation test. Inclination angle of cutting edge nor number of mill blades have not been considered, that is why it has been assumed tool model as cylinder (fig. 3).

Applied testing methodology is suitable for implementation in many CAD systems. Tool model was moved by value of feed per revolution - $f$, along a tool path, which was offset curve in relation to machining edge of workpiece.

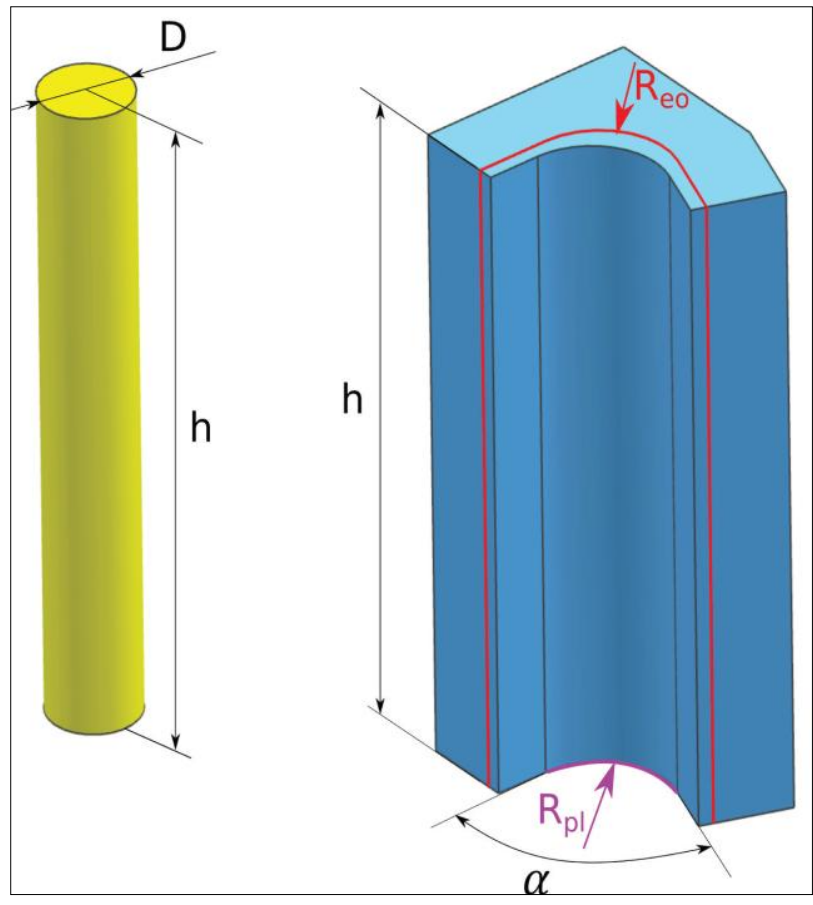

Fig. 3. Parametric models adopted for simulation tests: $D$ - tool diameter;

$h$ - height of the working part, the tool and the workpiece; $\alpha$ - angle between adjacent walls of the workpiece;

$R_{\mathrm{pl}}$ - radius of the rounding of the blank;

$R_{\text {eo }}$ - radius of the rounding of the workpiece

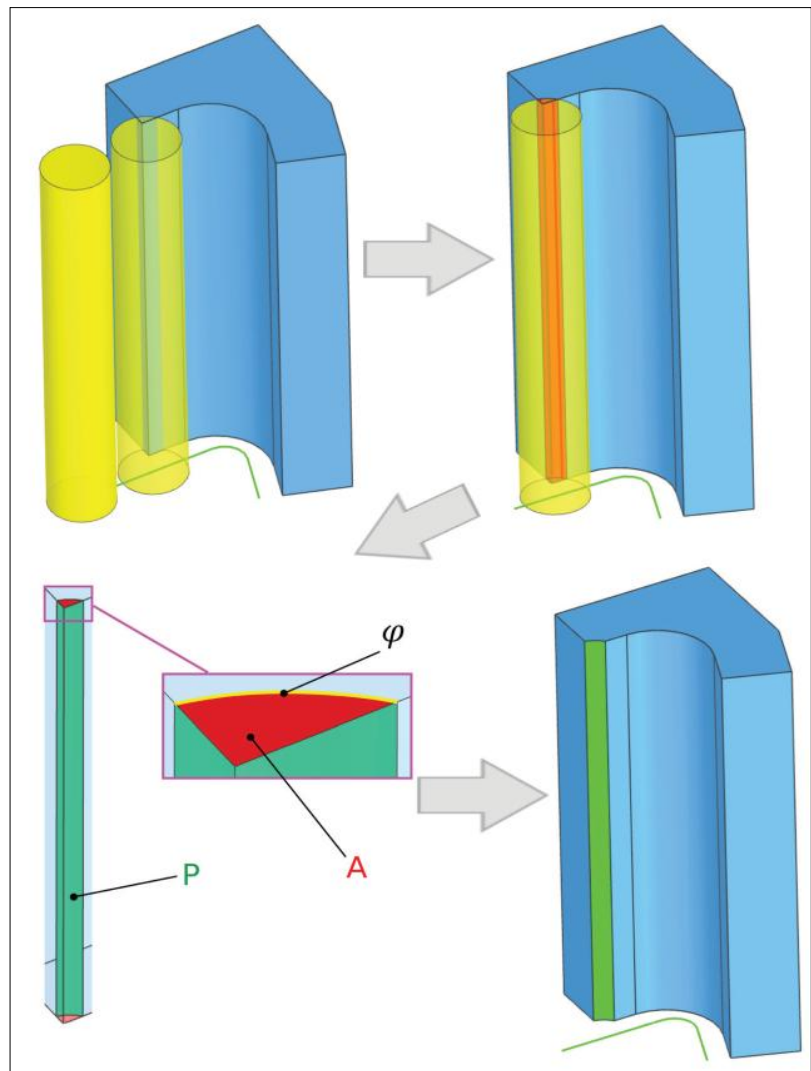

Fig. 4. Scheme of simulation tests with measurement of wrap angle $-\varphi$, cross-sectional area of the machined layer $-A$ and contact area of the tool with the workpiece $-P$

It has been assumed constant feed referring to the centre of tool. The first step was establishment of a intersection part of tool model and blank. On this basis was measured: wrap angle $-\varphi$, cross-sectional area of the machined layer $-A$ and contact area of the tool with workpiece $-P$. Then the solid forming the common part was subtracted from the semi-finished product. The operations have been carried out in many iterative steps in order to obtain finished product (fig. 4) [1, 2]. 


\section{Multi-pass strategy}

As simplification, multi-pass strategy with only two paths has been considered. Tools paths in multi-pass strategy are usually generated based on offset curves from workpiece edges, in the same way as traditional tools paths (fig. $5 a$ ). These strategies are very simple for implementation in any control system, without using special CAD/CAM software. This solution completely eliminates the problem of cutting width change, but still there is increased wrap angle in corners. To minimise this effect may be used smaller radius of the rounding occurred as a result of the first finishing pass. It is necessary to assume different radius than result from offset path radius. During the last pass is possible to obtain the smallest allowance, if in the previous passes will be use the smallest radius - equal to tool radius (fig. $5 b$ ). However, that there is a problem of the sharp corner existence on the path for passes preceding finishing passes $[4,6,7]$.

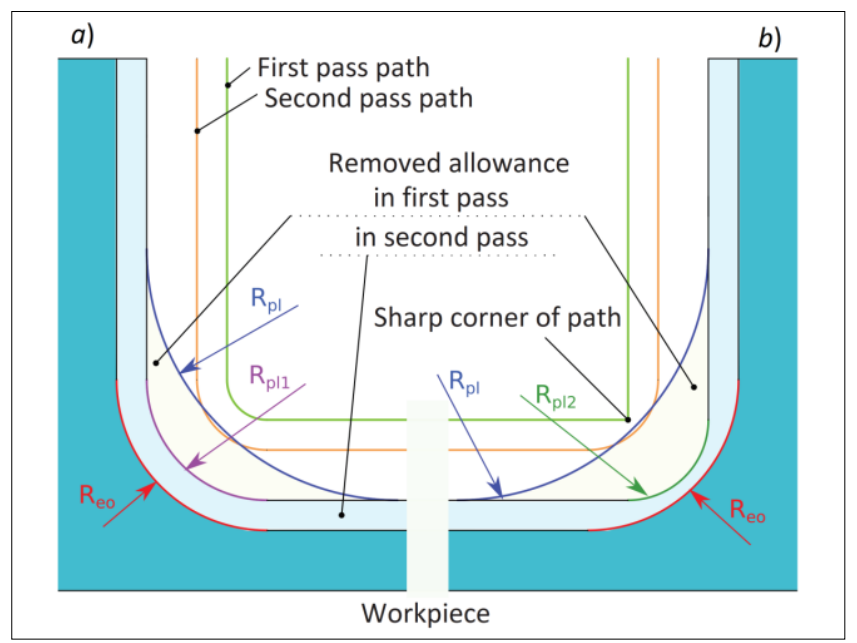

Fig. 5. Diagram of multi-pass strategies: $a$ ) strategy $A$ - with constant cutting width; b) strategy $B$ - with variable cutting width, where: $R_{\mathrm{pl} 1}$ - rounding of the blank for the finishing pass of strategy $A$, $R_{\mathrm{pl2}}$ - rounding of the blank for the finishing pass of strategy $B$

\section{Tests results}

Series of simulation tests have been run for variable blank radius $-R_{\mathrm{pl}}$ and variable angle between workpiece walls $-\alpha$. It was assumed constant values: $f=0,5 \mathrm{~mm} / \mathrm{rev}, a=1 \mathrm{~mm}, D=6 \mathrm{~mm}, R_{\mathrm{eo}}=5 \mathrm{~mm}, h=30 \mathrm{~mm}$. All three measured values: wrap angle $-\varphi$, cross-sectional area of the machined layer $-A$ and contact area of the tool with the workpiece $-P$, have had identical courses and only values and units were different, thus only the wrap angle value was shown (fig. 6).

With increase of blank rounding radius is visible an increase in the wrap angle. Rounding increase from 5 to 9 $\mathrm{mm}$ produce an increase of wrap angle by $35 \%$. Similarly - but with different course - it can be noted an increase in the wrap angle with the decrease of angle between model walls. It is worth noting that an decrease of angle between workpiece walls from $90^{\circ}$ to $80^{\circ}$ results in a change of mill wrap angle approx. $4^{\circ}$, where the change in angle workpiece walls form $40^{\circ}$ to $30^{\circ}$ would increase wrap angle up to $20^{\circ}$.

In order to analyse the multi-pass strategy it was assumed constant parameters: $f=0,5 \mathrm{~mm} / \mathrm{rev}, D=6 \mathrm{~mm}$, $R_{\mathrm{pl}}=7 \mathrm{~mm}, R_{\mathrm{eo}}=5 \mathrm{~mm}, \alpha=90^{\circ}$. Two passes were used and two strategies were tested ( $A$ and $B$ ) (fig. 7).

It could be said that no every modification mode will achieve desired result. In the case of strategy $A$, it should be note a high momentary increase in the wrap angle at the first pass, and in the case of strategy B this hop is larger than the initial one in single-pass strategy. This increase is due to sharp corner of tool path - when it is reached, the tool has the maximum possible wrap angle. In both cases finishing pass showed a decrease in wrap angle by $25 \%$ in relation to single-pass strategy. For strategy $B$ - although measured value is almost identical with strategy $A$ - maximum wrap angle is kept half the time (compared to strategy A). This may be highly relevant where it is important to obtain the best surface quality of the workpiece.

It was verified that multi-pass strategies work in a similar way for a workpiece with more complex geometry. The strategy A has been selected as the most stable and it was assumed angle between the workpiece walls $\alpha=$ $70^{\circ}$ (fig. 8). 

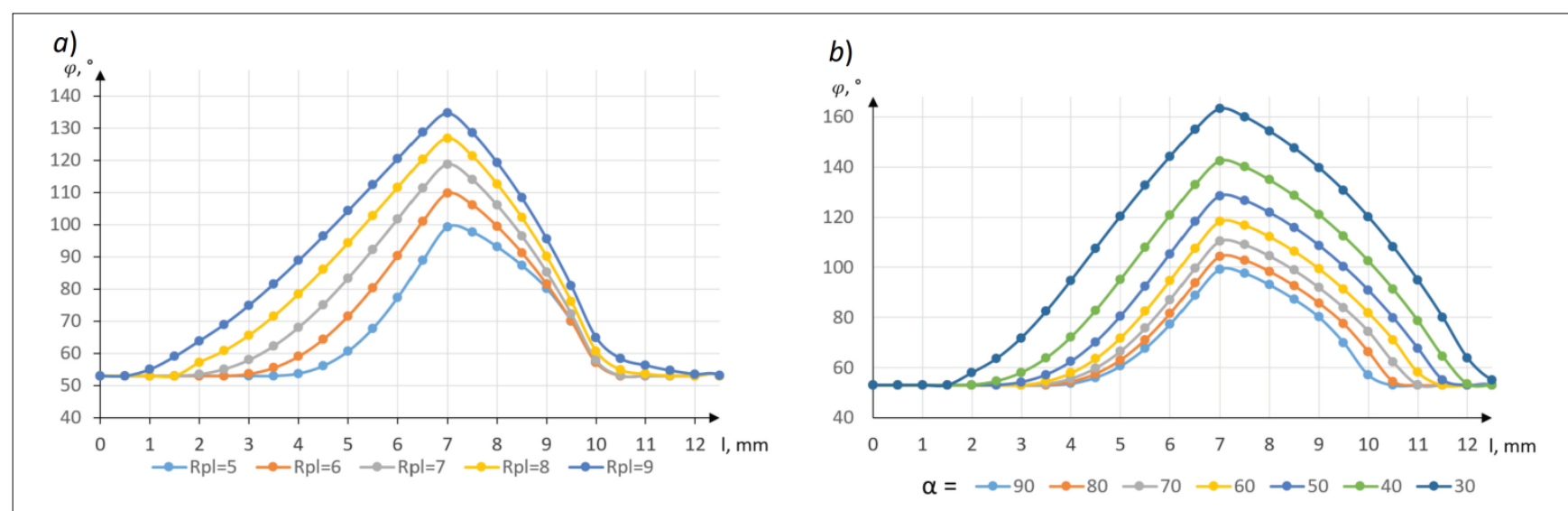

Fig. 6. Change of wrap angle $\varphi$ depending on the traveled distance of the tool $l$ for: $a$ ) for a variable radius of the blank $R_{\mathrm{pl}}$ and a constant $\alpha=90^{\circ}, b$ ) for a variable angle of inclination between the walls $\alpha$ and fixed radius of the blank $R$ pl $=5 \mathrm{~mm}$

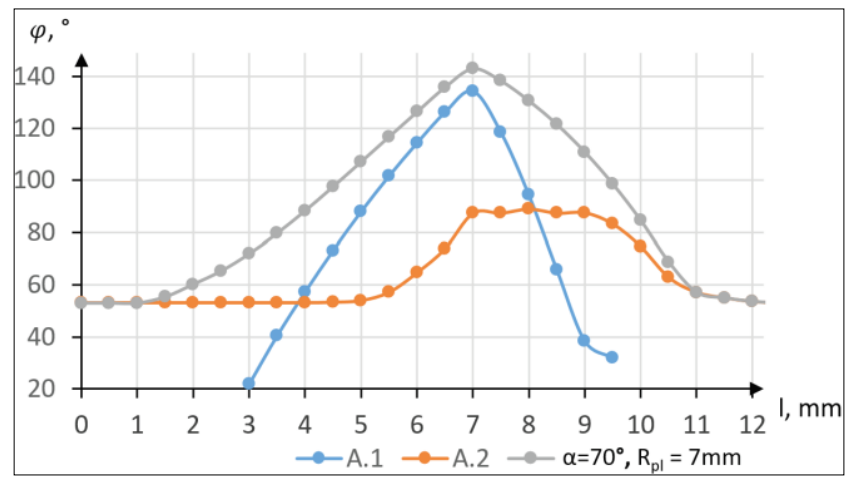

Fig. 7. Change in wrap angle $\varphi$ depending on the tool path $l$ traveled for $A$ and $B$ strategies

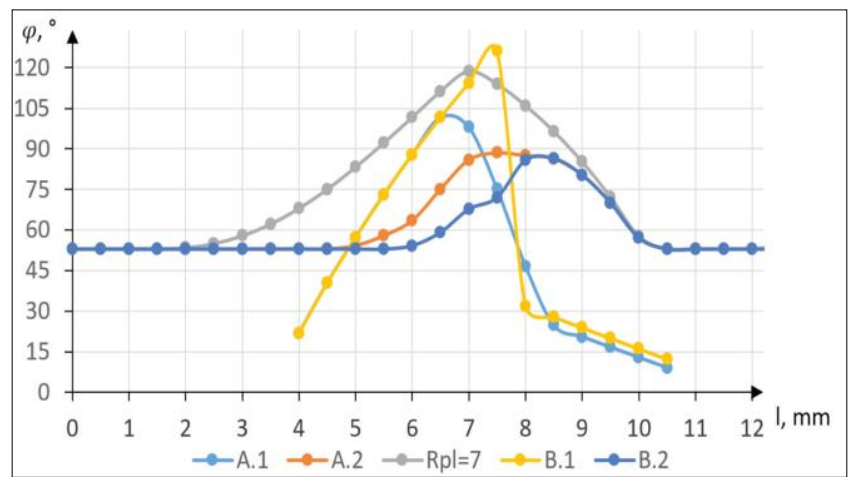

Fig. 8. Simulation results using a multi-pass strategy $A$ for a workpiece with an acute angle $\alpha=70^{\circ}$

\section{Conclusions}

The analysis indicates that tool wrap angle during internal corners milling may be reducing in several ways. Obtained characteristics confirm that it is possible to obtain a significantly smaller wrap angle for finishing pass also in case where angle between workpiece walls is smaller than $90^{\circ}$. If it is necessary to reduce the wrap angle in first pass (profiling), change the tool or feed modification is needed.

Presented multi-pass strategies are universal - are permitted to set on machine tool control system, even without special CAD/CAM software.

\section{LITERATURA}

[1] Boz Y., Erdim H., Lazoglu I. "A comparison of solid model and three-orthogonal dexelfield methods for cutterworkpiece engagement calculations in three- and five-axis virtual milling". International Journal of Advanced Manufacturing Technology. 81, 5-8 (2015): 811-823, https://doi.org/10.1007/s00170-015-7251-7.

[2] Burek J., Flejszar R. „Analiza warstwy skrawanej w obróbce elementów cienkościennych o złożonej geometrii”. Mechanik. 8-9 (2018): 778-780, https://doi.org/10.17814/mechanik.2018.8-9.132.

[3] Han X., Tang L. "Precise prediction of forces in milling circular corners". International Journal of Machine Tools and Manufacture. 88 (2015): 184-193, https://doi.org/10.1016/j.ijmachtools.2014.09.004.

[4] Sui S., Li Y., Shao W., Feng P. "Tool path generation and optimization method for pocket flank milling of aircraft structural parts based on the constraints of cutting force and dynamic characteristics of machine tools". International Journal of Advanced Manufacturing Technology. 85, 5-8 (2016): 1553-1564, https://doi.org/10.1007/s00170-015-8050-X.

[5] Yue C., Liu X., Ding Y., Liang S.Y. "Off-line error compensation in corner milling process". Journal of Engineering Manufacture. 232 (2016): 1172-1181, https://doi.org/10.1177/0954405416666901.

[6] Sandvik Coromant. „Milling - good practice. Setting solid foundations”. Application Guide (2015).

[7] Documentation: NX 11. 